\title{
1. Introducing theoretical perspectives on family business
}

\author{
Mattias Nordqvist, Leif Melin, Matthias \\ Waldkirch and Gershon Kumeto
}

\section{INTRODUCTION}

The field of family business research has grown immensely over the last couple of decades. From being a research field in the periphery of the management discipline, family business research today is well-recognised and studies are regularly published in top journals. Scholars tend to suggest that the overarching aim of the family business field is to create new knowledge '.. on one specific type of organizations - the family enterprises. These are the most prevalent form of business organizations in the world. In these organizations, the overlap between family and work systems is such that family members significantly influence the key decisions and direction of an enterprise, and vice versa' (Sharma et al., 2014 , p. 1). The unique feature of the family business field is that scholars focus on investigating and understanding the reasons, meanings, roles and impacts of the interaction between at least two systems: the family and the business. The mutual impact between these two systems give family enterprises specific characteristics that we rarely see in other types of businesses and organisations. A common definition of a family business is 'a business governed and/or managed with the intention to shape and/or pursue the vision of the business held by a dominant coalition controlled by members of the same family or a small number of families in a manner that is potentially sustainable across generations of the family or families' (Chua et al., 1999, p. 25).

The family business field has been accused of being traditionally a-theoretical and descriptive in comparison to some of its sister disciplines. But such an accusation is built on a selective reading of the field's early contributions. Many of the family business field's most central founding mothers and fathers rooted their work in theoretical foundations, even if they were also strongly guided by practice and by the 
challenges real family businesses and their members were facing (Sharma et al., 2014). Indeed, because of close association of the family and the business systems, family business scholars have been prompt to search for inspiration in various disciplines in order to find appropriate theories to apply in the pursuit to increase the understanding of family enterprises. Often scholars have realised, typically after engaging in a practice similar to what Van de Ven (2007) calls 'engaged scholarship' that in order to understand the influence of the family on the business, traditional organisation and management theories have not been enough (Sharma, 2004). As a result, researchers in the family business field were relatively early to use theories from for instance psychology, family studies and pedagogics. Another important realisation is that family businesses are not a homogeneous group of organisations. There are many different types of family businesses and in order to capture the similarities and differences among family businesses in relation to important topics and phenomena various theoretical perspectives are needed (Melin and Nordqvist, 2007).

However, while many different theories have been used during the growth of the family business research field, there are surprisingly few attempts to provide an overview of theories that may be of particular interest for the family business scholar. The most recent overview is the SAGE Handbook of Family Business (Melin et al., 2014) and the book you are now reading both builds on and adds to the Sage Handbook. In this book, our focus is to provide an overview of some common theories that have been used in family business research, and an overview of some other theories that we believe hold great potential to further the progression of our field, but so far have not been used extensively. This is because we concur with Sharma et al. (2014, p. 15) that '[a]s rich insights can be gained from diversity, we expect to see a multiplicity of theoretical perspectives being adopted to strengthen and deepen our understanding of the heterogeneity within the family businesses and building the usable knowledge on these enterprises'.

Thus, the purpose of this book is to serve as a point of departure and source of inspiration for scholars who seek an overview of some of the most interesting and relevant theoretical perspectives for contemporary family business studies. The book contains 13 chapters following this one, each treating one particular theoretical perspective. The chapters have been designed to give a brief overview of the theoretical perspective, a review of the most important examples of family business research using the perspective, and a proposal for ideas and guidelines for future research. At the end of this chapter, there is an introduction to each of the following chapters, and a short background description of how the idea 
of the book was first born and how it materialised into the publication you are now reading. However, we will first devote a few sections to go deeper into the topic of theoretical perspectives in family business studies.

\section{WHAT IS A THEORETICAL PERSPECTIVE?}

There are many different ways of defining what a theory is. At the broadest level we can identify at least three different ways of approaching the meaning of theory and the role of theory in social sciences. The first approach is theory as what underlies research design (Alvesson and Sköldberg, 2009). Here researchers focus on issues regarding ontology (that is, what constitutes reality), epistemology (that is, on what basis can we claim we create valid knowledge of that reality) and methodology (that is, how we go about creating that knowledge). The second approach is theory as the systematic integration and presentation of findings and new insights that emerge from a particular conceptual or empirical study (Whetten, 1989). Here, the scholar proposes a theory or a model as the final results of the study. The theory may adapt, revise or confirm previous theory. In some rare cases the results may also constitute a completely new theory. The third approach is theory as a lens (Astley and Van de Ven, 1983). This refers to the application of theory as an existing framework that can help the scholar to understand or explain how the world works. Most chapters in this book follow the third approach to theory, while some chapters also represent the first approach reflecting on ontology and epistemology.

In our focus on theory as a lens, we have chosen to use the notion of 'theoretical perspective' rather than 'theory'. The reason is that in our view the label 'theory' often carries with it a connotation of a fully fledged model or predictive framework of relationships that is fairly rigid. This is the case even for a theory in its simplest form defined as an explanation - an answer to the question why (Sutton and Staw, 1995) regardless of how this explanation is structured and communicated. According to Bacharach (1989, p. 496) 'a theory is a statement of relations among concepts within a set of boundary assumptions and constraints. It is no more than a linguistic device used to organize a complex empirical world.' As such, the underlying purpose of a theory is to organise and communicate knowledge about a particular phenomenon. The primary goal of a theory can be seen as answering the questions how, when and why, unlike the goal of a description, which is to answer 
the question of what. All theories are limited by their bounding assumptions (Dubin, 1978), implying that one theory cannot explain everything. This is a good reason for talking about a theoretical perspective that offers one particular view of the world depending on from which position or through which lens the world is looked.

Our intention with the use of theoretical perspective is also to use a somewhat more relaxed term that also includes frameworks, interrelated concepts and language, propositions and models that may constitute a way of seeing and understanding phenomena without necessarily meeting all the formal qualifications of being a theory. Indeed, what actually constitutes a theory is still debated and is sometimes a rather controversial topic of scholarly discussion. Our intention in this introduction chapter is not to answer the question of what a theory is, but rather outline some important aspects of how we understand the notion of theoretical perspective.

At the most general level, a theoretical perspective to us is a collection of underlying assumptions about a reality or phenomenon that guides the questions we ask about this reality or phenomenon, and as a result influences the answers we get on those questions. Theoretical perspectives are important tools for researchers because the assumptions underlying every theoretical perspective we adopt direct our attention and provide frameworks for interpreting what we see and observe. The understanding we gain from researching a particular phenomenon is always associated with the theoretical perspective we apply. Here, it is also important to underline that spatial and temporal boundaries restrict the empirical generalisability of the theory (Bacharach, 1989). This means that scholars need to keep in mind, and take into account, the 'when' and 'where' of theoretical perspective: the time and place in which a particular theoretical perspective was formulated and first appeared useful in order to better understand a phenomenon typically affecting the power of that perspective as a tool for understanding other phenomena. In our case, this is particularly important to keep in mind since family businesses tend to differ from other organisations in important ways (Gedajlovic et al., 2012) and at the same time differ among themselves (Melin and Nordqvist, 2007). In other words, theoretical perspectives that have been created to understand how a different type of organisation works might not be the best perspective to use - at least not before it has been revised and adjusted to respect the unique aspects of the family type of organisation.

Theoretical perspectives are important ways of seeing and understanding the world. Management and organisation theory has been blessed with many different theories. There are plenty of handbooks available 
that provide excellent overviews of the most common and popular theoretical perspectives in use on management and organisation theory. An important reason for the abundance of theoretical perspectives in this discipline is the insight that one perspective cannot be complete in its explanation of a particular phenomenon. This means that each understanding gained through a scholarly inquiry using a particular theoretical perspective can only be partial.

However, the fact that each theoretical perspective will only offer a partial and insufficient understanding is not completely unproblematic. The reason is that each theoretical perspective typically is associated with major debates that relate to how we perceive and act in social and organisational contexts. Put differently, theoretical perspectives are based on different assumptions of human nature, about social structures and about how society is constituted, for instance in terms of power relations. As a way to better understand how theoretical perspectives in management and organisation are related to various assumptions about human nature and social structures, Astley and Van de Ven (1983) suggest that it is important to uncover and reflect upon the underlying assumptions of each theoretical perspective. They suggest that there are at least four different schools of thoughts, or broader categories of theoretical perspectives, in which most perspectives can be placed. These categories differ depending on their focal level of analysis (macro or micro), and their relative emphasis on a deterministic versus a voluntaristic assumption of human nature. The classic duality between social determinism and free will is thus present in Astley and Van de Ven's categorisation of different theoretical perspectives. The insight from their framework is that it is important for scholars to pay attention to the underlying category that a particular theoretical perspective belongs to. Selecting a particular theoretical perspective means selecting a particular way of seeing. The way we see and understand the role of human actors, such as managers or board members in an organisation, will be closely associated with the room of action our chosen theoretical perspective gives to human actors. Some theoretical perspectives, such as organisational ecology, give very little room for action while others, such as the theory of planned behaviour, gives a lot of room for action for individuals (to take two examples from this book).

Scholars should therefore keep in mind that proponents of a particular theoretical perspective '... are engaged in political efforts to gain dominance within the discipline as a means of imposing their own conceptions of reality on the practical events of social life' (Astley and Van de Ven, 1983, p. 270). Indeed, Max Weber (1986) has already observed that the value-laden nature of assumptions in theoretical works 
can never be eliminated. This means that the basis upon which we select theoretical perspectives is closely related to our personal interests, values and priorities.

However, it should be noted that it is not only personal values and interests that tend to guide the selection and use of a particular theoretical perspective. First, we have the paradigmatic influence on individual researchers, where predominant, often not articulated taken-for-granted views on what is right and wrong regarding ontological and epistemological issues related to a field of research shape the practices of scholars, including their choice of theory (Kuhn, 1962; Törnebohm, 1978). Related to paradigm, professional norms and institutional expectations within the field of management and organisation have been highlighted to play an important role with regards to how we select theoretical perspectives. By 1980, Gareth Morgan was criticising the taken for granted-ness in organisation studies, with too much emphasis on puzzle solving. Instead: 'A theoretical and methodological pluralism which allows the development of new perspectives for organizational analysis is suggested. While orthodoxy is based upon a few metaphors characteristic of the functionalist paradigm, metaphors characteristic of other paradigms, which challenge the ground assumptions of orthodoxy, are shown to have much to offer' (Morgan, 1980, p. 605). More recently, Alvesson and Sandberg (2013) observe and critique the tendency among many scholars today to conform to a practice of 'gap-spotting' research rather than 'assumption-challenging' research. Inherent in this tendency is a preference for designing research projects based on established theoretical perspectives that at the most offer minor contribution to the accumulation of knowledge. This leads to a '... troubling shortage of novel ideas and really strong contributions to management studies' (Alvesson and Sandberg, 2013, p. 128). The main problem that these authors attempt to address is that there are very few new and exciting theories being developed in the discipline of management and organisation. More scholars should dare to build research projects where they select new theoretical perspectives that are challenging the dominant theoretical perspectives. Such a practice will increase the chances to see new interesting insights emerging. Indeed, ' $\ldots$ it is widely recognized that a theory attracts attention and becomes influential if it challenges our current assumptions, rather than reinforcing them by thoroughly and systematically filling a gap in existing literature' (Alvesson and Sandberg, 2013, p. 129).

However, currently there is a dominance in letting professional norms and institutional expectations steer us in a direction where, as Miller et al. (2009, p. 278) note, work is encouraged on '... topics that fit neatly 
within today's popular theories and allow the development and tweaking of those theories'. In conclusion, the lesson is that the formation and selection of specific theoretical perspectives are not done in isolation from the values and priorities of individual scholars, nor from the norms and expectations brought upon us by peers, departments, institutions and other authorities that in different ways regulate our scholarly work.

Another important aspect to keep in mind when we focus on theoretical perspectives in management and organisation, and more specifically in family business studies, is that we often borrow concepts and theories from other disciplines and apply them in our own area (Whetten et al., 2009). This is a natural and useful practice if theoretical perspectives from, for instance, sociology, psychology and economics are useful for understanding the phenomenon that we are interested in inquiring about in our field. However, a crucial point to keep in mind is that scholars should be careful to transfer theoretical perspectives created in another discipline to another area without making necessary adjustments to the underlying assumptions and characteristics of the new area (Whetten et al., 2009). Yet, when such an adaption of the original theoretical perspective has been done in a new context, it is also likely that research into a new discipline or field can contribute back to the original theory, even though a mere application of a theoretical perspective derived in one context and applied to another shall not be seen as enough for a theoretical contribution (Whetten, 1989). In summary, the inter-exchange of theoretical perspectives between disciplines and fields should be encouraged. As we shall see in the next section, the family business field represents an area which is particularly rich in opportunities for crossapplication of theoretical perspectives.

\section{THEORETICAL PERSPECTIVES IN FAMILY BUSINESS STUDIES}

Davis and Marquis (2005) note that large organisations are the most powerful actors in today's society as a result of their large influence on people's lives as employees, consumers, investors and clients. As a consequence, organisation theory is today reckoned as the 'queen of social sciences, uniquely able to explain the dominant social structures of our times' (Davis and Marquis, 2005, p. 332). Interestingly, if we agree that family businesses represent the most common form of organisations in the world, theories of family businesses should be particularly important and influential today as they deal with a better understanding of a type of organisation that particularly affects many people around the world. 
Indeed, the phenomenon of family business includes both general aspects of business firms and more specific aspects that organisations with this type of ownership share. Among the specific aspects, a key distinction is that studies of family business are based on the overlapping systems of family and business, including the extent and nature of family members' involvement in the business. Furthermore, the family business as a specific population of business firms shows a significant heterogeneity regarding for example age, size and industry. All this implies both the potential and the necessity of applying a number of different theoretical perspectives to understand and build knowledge about what we describe as family businesses. This gives us reasons for (1) borrowing theories to explain family business, (2) using family business evidence to further develop or modify existing theories, as well as (3) using unique family business findings to generate new theory. Let us take some examples to illustrate these three alternative routes of theory development (and combinations of them) in the family business context.

The most frequent use of borrowing theories into family business studies concerns agency theory and resource based theory (both theories are represented in this book). When applying them in the family business context, the result has been important contributions to the emerging knowledge base in the field of family businesses (Sharma et al., 2014). However, there are also risks with borrowing established theories, for example when borrowing means that scholars deeply rooted in other disciplines 'invade' family business research with assumptions and methodologies that lead to quite narrow contributions, and expectations that family business scholars should conform to those disciplinary norms (Birkinshaw et al., 2014). Regarding the resource based view, the application has also lead to the novel conceptualisation of familiness, meaning the bundle of resources that are distinctive to a business firm because of a family's involvement (Habbershon and Williams, 1999). Another increasingly borrowed theory is the social capital theory that also has resulted in a specific development around family capital (Arregle et al., 2007; Danes et al., 2009). As a final example, the corporate entrepreneurship perspective has increasingly been shown to be highly relevant when applied to understanding family business strategy over generations (Kellermanns and Eddleston, 2006).

Regarding theories that have great potential for being further developed or modified by empirical evidence from family business studies we mention two: organisational identity theory (Whetten et al., 2014) and theory on emotions in organisations (Brundin and Härtel, 2014), because of the richness of identity issues and emotional dimensions in both daily 
family business life and in situations of several typical critical incidents in family businesses.

Finally, we argue that family business studies certainly can contribute to new management and organisation theory, both new theory that may be specific to the family business context and new theory that can be generalised to the broader field of management theory. An example of the former is the socioemotional wealth perspective quite recently introduced, which after less than ten years seems to establish itself as a theory with power to explain many decisions made in family businesses: 'major managerial choices will be driven by a desire to preserve and enhance the family's socioemotional wealth' (Gómez-Mejía et al., 2011, p. 656).

The capacity for developing new theory in management research seems to be low (Birkinshaw et al., 2014). Existing theory fails to explain many aspects of the world of business firms leading to a quest for increased efforts to develop new theory. Here the phenomenon of family business, with both wide distribution and predominant characteristics, makes a case for new theory development. Students of family business have a challenge to break new ground, being co-responsible in a collective effort in management research to develop novel theoretical contributions (Cornelissen and Durand, 2014). Such theory building may not only be enlightening for the understanding of family business but possibly also travel to other parts of management and social sciences.

However, in the future development of family business as a field of study, a scholarly conversation on the boundaries and focus of family business studies is needed, as there presently is no agreement on what constitutes the field of family business (cf. Gartner's (2001) discussion on 'blind assumptions in theory development' in entrepreneurship). Such a conversation would also include what theories are appropriate for the building of family business knowledge. The aim would not be to develop the family business theory, but rather to promote a relevant diversity where innovative research designs and questions will lead to a rich and connected set of theories that bring light to the complex phenomenon of family business.

To conclude, the field of family business studies is very attractive for the intellectually curious scholar with opportunities for applying a wide range of theoretical lenses. Rich opportunities are available to test theories developed in management and family sciences in the context of family businesses' (Sharma and Melin, 2015, p. xliii). At the same time there are excellent opportunities for developing new theoretical formulations based on specific features of family firms (Craig and Salvato, 2012). 


\section{THE BACKGROUND TO THIS BOOK}

As we write this introduction, it has been about a year since we first considered developing this book. The idea for the book developed during a doctoral course in December 2013, organised by the Centre for Family Enterprise and Ownership (CeFEO) at Jönköping International Business School in Sweden, and funded by a generous donation from the Henry and Sylvia Toft Foundation. Professors Mattias Nordqvist and Leif Melin invited 16 doctoral candidates from all over Europe as well as Professor Dawn DeTienne from Colorado State University, US and Dr Philipp Sieger from University of St Gallen, Switzerland for a three-day workshop to discuss 'Central Perspectives and Themes in Family Business Research'. In an old hotel once featured in a movie by Ingmar Bergman, located by Lake Vättern not far from Jönköping, Sweden, we found a perfect venue. The doctoral course proved to be a great success with intense discussions taking place late into the night. Even though the group of $\mathrm{PhD}$ candidates convening in Sweden was diverse in almost every aspect - their country of origin, their diverging topics and methodological stances, or the progress in their doctoral studies - they still were united by their common interest in family business. It was this mix of variety and focus that made for a thrilling course, and we hope to capture this spirit in the book you are reading.

One of the core assignments of the workshop was for each $\mathrm{PhD}$ candidate to review and present a theory that could potentially further family business studies. Initially supposed to be a complement to the main task of the course, the presentations served both as an introduction to diverse theories as well as a starting point for animated discussion about potential research topics. Several of the theories, such as agency theory or culture theory, have been broadly used within family business studies, while other theories, such as critical pedagogy or kinship theory have been used to a lesser extent. The origin of the theories is also diverse, as some of them, such as behavioural theory, are deeply rooted within organisational studies, while others, such as social identity theory, have only latterly been adapted to study organisational phenomena. What all these theories have in common, however, is that they offer ample opportunity for new and exciting research on family, business and ownership issues. It is this spirit of discovery and inspiration that our authors try to depict in their chapters.

After the doctoral course in December 2013, the contributors of this book met again in April 2014 at Jönköping International Business School with revised versions of the chapters. Alongside the feedback from the 
four editors, for the next round of submission, Dr Daniel Pittino from the University of Udine, Italy, reviewed all chapters and added his constructive recommendations for how to improve them even further. Two more rounds of submission through the summer and autumn have helped to shape the chapters into their current form, and we are proud about the high standards that all chapters meet. We are also happy that this book is published in 2015, which is the year in which our centre, CeFEO, celebrates its tenth anniversary. The next section will briefly introduce the book's chapters.

\section{THE CHAPTERS IN THE BOOK}

The chapter by Giuseppe Criaco takes a macro-perspective on family firms through an organisational ecology perspective. The theory has long been used to study the survival of organisations; however, few studies have focused on how this perspective can be applied to investigate similar topics in distinct organisational forms, such as family businesses. Criaco addresses this gap by applying the organisational ecology perspective to the study of family businesses. In his chapter he explores how the environment could potentially influence the survival of family businesses. Criaco provides a thorough explanation as to why certain environments and industries are more beneficial for family firms than others and convincingly argues why 'family' may be an interesting new level of analysis for studies utilising organisational ecology perspective.

Moving towards a firm-level perspective, the chapter by Ambra Mazzelli builds upon Cyert and March's classic contribution, A Behavioral Theory of the Firm. Even though behavioural theory has been adapted to family business research, Mazzelli argues that its treatment has been quite fragmented, which is why she reintroduces several of the main concepts of behavioural theory to family business research. In particular, the link between organisational goals, aspirations and problemistic search and how they influence behaviour in family firms is in focus, as such aspirations are influenced by the owner family and their particularistic goals. Mazzelli convincingly argues that a refocus on the original concepts allows new insights to be gained into what drives organisational search and which characteristics of the dominant coalition influence goal setting and aspirational choice, thereby opening new routes for research into family firms and general understanding of firm behaviour.

Agency theory, which builds on several of the key contributions of behavioural theory, is one of the dominant organisational theory perspectives that is applied to and further developed in family business research. 
Andreas Kallmuenzer discusses the use of the agency theory in family business research with a particular focus on how business and family preferences form a unique situation in family firms, leading to multiple sources of agency costs that negatively influence performance. He reviews the most-cited research in family firms using agency theory, highlights three trends of agency research and demonstrates the relational and altruistic aspects of family firms as sources of agency costs. Kallmuenzer argues that an agency perspective could yield new insights when examining the relationship between entrepreneurial attitudes and performance.

Gershon Kumeto discusses the behavioural agency theory and its family business variant the 'socioemotional wealth' construct, which are fast emerging theoretical perspectives in the family business field. The behavioural agency theory builds on agency theory to offer more precise explanations on why decision makers prefer some strategic choices over others. The use of this theory in family business research has been very limited because some of its fundamental assumptions do not always hold in the family business context. In his chapter, Kumeto conducts an interesting analysis of how the fundamental concepts of the behavioural agency theory are reflected in the socioemotional wealth construct and discusses how family business scholars have so far implemented socioemotional wealth. The analysis in this chapter offers many opportunities on how both the behavioural agency theory and the socioemotional wealth construct can be used in further research to contribute to both the family business and the general management literature.

Andrea Kuiken in her chapter discusses how the theory of planned behaviour could be further used in family business research. Current application of the theory in the family business context is limited to succession issues in the family business strictly at an individual level. Kuiken argues that the application of the theory of planned behaviour at the family and business level will be useful to understand how interactions in the family and business result in the creation of common beliefs and intentions. These intentions would accordingly shape strategic decisions in family firms and make family firms an interesting context for research utilising the theory of planned behaviour. Regarding strategic decisions, this perspective opens up future research avenues on diverse issues, such as corporate entrepreneurship and the internationalisation of family firms.

Venturing out from the established variance approach, the chapter by Emanuela Rondi furthers a stronger focus on process thinking in family business research as the author calls for more sensitivity towards issues of time. By focusing on a becoming ontology, family business research 
would be better equipped to track and understand changes in all subsystems of the family firm. Since process research allows the establishment of temporal relationships between variables, previously static relationships may enter a temporal flux. Rondi points out several advantages and contributions that derive from making use of a process perspective, such as a stronger focus on the micro-processes of change or the relationship between process and social interaction in the family firm. In particular strategy-as-practice, due to its focus on micro-activities, may be an approach that would allow the uncovering of organisational processes and for research with more impact on practitioners.

In his chapter, Matthias Waldkirch argues for a stronger use of social identity theory in family business research, as it links parts of the personal identity to membership in social groups. Issues of identity have always been prevalent in family business research, and social identity theory has also been used to examine, for instance, the influence of the family on the business or the balance between family and business identities. Yet, as Waldkirch points out, the theory has not been used to its fullest potential, allowing for several future research opportunities. Regarding diverse issues such as succession, intra-family conflict, or non-family management socialisation, social identity theory may be able to foster new insights. Moreover, analysing the social category of ownership may allow for a link to be built to macro-ownership practices among different family firms.

Another lens that has been strongly associated with family firms is organisational culture. In his chapter, Rocky Adiguna introduces culture, tracing it back to its origins in organisational research. He shows how the use of culture in family business research moved from a positivistic use of culture as a clear-cut variable towards a more interpretivist perspective on culture. Using culture as a root metaphor in family business research would, according to Adiguna, allow attention to be centred on organisational processes instead of outcomes. Moreover, Adiguna notes the importance of not only seeing family business culture represented by the dominant coalition, but also investigating non-family employees' perspectives. Just like Rondi in her chapter on processual research, Adiguna also sees the future of cultural studies in examining the processes of how culture is built and how it affects the business and its members.

Placing family relationships at the centre of attention, the chapter by Naveed Akhter reviews and synthesises prior work on kinship in family firms and opens up future research avenues for this interesting topic. The chapter shows that kinship is highly relevant in family firms by revisiting the concepts of family and kinship as well as by scrutinising several definitions of family firms. Akhter explores important aspects related to 
kinship in family firms, such as continuity of generations, succession, inheritance and resource provision. Building upon these four functions of kinship in the family business context, Akhter suggests several promising future research opportunities by which kinship can expand our understanding of family businesses phenomena.

Karin Staffansson Pauli casts a critical view on family business research by investigating how gender has been researched and operationalised. Even though women play a central role in family firms, they are still facing obstacles such as stereotypes and inconspicuousness. Furthermore, Staffansson Pauli argues that many studies are missing a deeper contextualisation that may link, for instance, gendering processes in family and business to societal developments and culture. Family business research has not properly addressed these issues, as most studies have focused on gender as a simple variable instead of examining it as being constructed in organisational dialogue. Therefore, Staffansson Pauli argues that focusing on how women construct femininity may help to leave the predominant male discourse in family business research, and allow understanding of how gender is accomplished.

Building on the work by Freire on critical pedagogy theory, Henrietta Nilson argues that a more critical perspective on family business is necessary to understand the underlying forces that shape both business and family. She criticises the common banking view inherent both in family business practice and in research, which does not see education and dialogue as happening between equals, but shapes a dichotomy between the 'knowing teacher' and the 'ignorant child'. In particular Freire's idea of critical dialogue allows issues to be seen from a fresh perspective, thereby revealing forces such as repression or relations of asymmetry, which are otherwise often under cover in family business research. In shaping such critical dialogue, the researcher may take an important role through participative approaches, helping to reveal such 'limited situations' to the family members.

In her chapter, Albertha Wielsma calls for a stronger focus on issues of reputation in family firms, as many phenomena and characteristics inherent in family firms are naturally connected to questions of reputation and image. Therefore, diving further into issues of reputation may allow new insights to be gained into the behaviour of both family businesses and their members, which otherwise would be hard to explain. As Wielsma explicates, family business may be a fertile context for research on corporate reputation, as the role of non-economic goals as drivers of reputation is more pronounced in family firms. Accordingly, Wielsma sees great potential in the mutual inclusion of family business research and reputational studies. 
Closing the book, Per Hansson presents the classic view of the company, which focuses on the internal capabilities of a firm. The theory has met with great response in the field of family business, outlining the idiosyncratic resources of family firms, as Hansson's review shows. Moving towards potential opportunities for future research, Hansson proposes to use a resource based perspective on the family as a unit of analysis, seeing it as a distinct organisation in itself. Taking such a perspective may help clarify, on the one hand, the influence of the family on the business; on the other hand, it may allow heterogeneity between family firms to be explained. Furthermore, research on family firms may enlighten the general discussion regarding how to orchestrate resources to achieve a balance between economic and non-financial goals.

\section{REFERENCES}

Alvesson, M. and Sandberg, J. (2013), 'Has management studies lost its way? Ideas for more imaginative and innovative research', Journal of Management Studies, 50 (1), 128-52.

Alvesson, M. and Sköldberg, K. (2009), Reflexive Methodology: New Vistas for Qualitative Research, 2nd edn, Los Angeles and London: SAGE.

Arregle, J.-L., Hitt, M. A., Sirmon, D. G. and Very, P. (2007), 'The development of organizational social capital: attributes of family firms', Journal of Management Studies, 44 (1), 73-95.

Astley, W. G. and Van de Ven, A. H. (1983), 'Central perspectives and debates in organization theory', Administrative Science Quarterly, 28 (2), 245-73.

Bacharach, S. B. (1989), 'Organizational theories: some criteria for evaluation', The Academy of Management Review, 14 (4), 496-515.

Birkinshaw, J., Healey, M. P., Suddaby, R. and Weber, K. (2014), 'Debating the future of management research', Journal of Management Studies, 51 (1), $38-55$.

Brundin, E. and Härtel, C. E. J. (2014), 'Emotions in family firms', in Melin, L., Nordqvist, M. and Sharma, P. (eds), The SAGE Handbook of Family Business, 1st edn, Thousand Oaks, CA: SAGE, pp. 529-48.

Chua, J. H., Chrisman, J. J. and Sharma, P. (1999), 'Defining the family business by behavior', Entrepreneurship Theory and Practice, 23 (4), 19-40.

Cornelissen, J. P. and Durand, R. (2014), 'Moving forward: developing theoretical contributions in management studies', Journal of Management Studies, $\mathbf{5 1}$ (6), 995-1022.

Craig, J. B. and Salvato, C. (2012), 'The distinctiveness, design, and direction of family business research: insights from management luminaries', Family Business Review, 25 (1), 109-16.

Cyert, R. M. and March, J. G. (1963), A Behavioral Theory of the Firm, Englewood Cliffs, NJ: Prentice-Hall. 
Danes, S. M., Stafford, K., Haynes, G. and Amarapurkar, S. S. (2009), 'Family capital of family firms: bridging human, social, and financial capital', Family Business Review, 22 (3), 199-215.

Davis, G. F. and Marquis, C. (2005), 'Prospects for organization theory in the early twenty-first century: institutional fields and mechanisms', Organization Science, 16 (4), 332-43.

Dubin, R. (1978), Theory Development, New York: Free Press.

Gartner, W. B. (2001), 'Is there an elephant in entrepreneurship? Blind assumptions in theory development', Entrepreneurship: Theory \& Practice, 25 (4), 27-39.

Gedajlovic, E., Carney, M., Chrisman, J. J. and Kellermanns, F. W. (2012), 'The adolescence of family firm research: taking stock and planning for the future', Journal of Management, 38 (4), 1010-37.

Gómez-Mejía, L. R., Cruz, C., Berrone, P. and De Castro, J. (2011), 'The bind that ties: socioemotional wealth preservation in family firms', The Academy of Management Annals, 5 (1), 653-707.

Habbershon, T. G. and Williams, M. L. (1999), 'A resource-based framework for assessing the strategic advantages of family firms', Family Business Review, 12 (1), 1-25.

Kellermanns, F. W. and Eddleston, K. A. (2006), 'Corporate entrepreneurship in family firms: a family perspective', Entrepreneurship Theory and Practice, $\mathbf{3 0}$ (6), 809-30.

Kuhn, T. S. (1962), The Structure of Scientific Revolutions, 1st edn, Chicago, IL: University of Chicago Press.

Melin, L. and Nordqvist, M. (2007), 'The reflexive dynamics of institutionalization: the case of the family business', Strategic Organization, 5 (3), 321-33.

Melin, L., Nordqvist, M. and Sharma, P. (eds) (2014), The SAGE Handbook of Family Business, 1st edn, Thousand Oaks, CA: SAGE.

Miller, D., Greenwood, R. and Prakash, R. (2009), 'What happened to organization theory?', Journal of Management Inquiry, 18 (4), 273-9.

Morgan, G. (1980), 'Paradigms, metaphors, and puzzle solving in organization theory', Administrative Science Quarterly, 25 (4), 605-22.

Sharma, P. (2004), 'An overview of the field of family business studies: current status and directions for the future', Family Business Review, 17 (1), 1-36.

Sharma, P. and Melin, L. (2015), 'Editors' introduction: evolution and scope of family business studies', in Sharma, P. and Melin, L. (eds), Family Business: Volume 1, Scope, Boundaries and Impact of Family Business, London: SAGE, pp. xxi-lii.

Sharma, P., Melin, L. and Nordqvist, M. (2014), 'Introduction: scope, evolution and future of family business studies', in Melin, L., Nordqvist, M. and Sharma, P. (eds), The SAGE Handbook of Family Business, 1st edn, Thousand Oaks, CA: SAGE, pp. 1-22.

Sutton, R. I. and Staw, B. M. (1995), 'What theory is not', Administrative Science Quarterly, 40 (3), 371-84.

Törnebohm, H. (1978), Paradigm i vetenskapsteorin, Göteborg, Sweden: Institutionen för vetenskapsteori.

Van de Ven, A. H. (2007), Engaged Scholarship: A Guide for Organizational and Social Research, Oxford and New York: Oxford University Press. 
Weber, M. (1968), Economy and Society: An Outline of Interpretive Sociology, Totowa, NJ: Bedminster Press.

Whetten, D. A. (1989), 'What constitutes a theoretical contribution?', The Academy of Management Review, 14 (4), 490-5.

Whetten, D. A., Felin, T. and King, B. G. (2009), 'The practice of theory borrowing in organizational studies: current issues and future directions', Journal of Management, 35 (3), 537-63.

Whetten, D. A., Foreman, P. and Dyer, W. G. (2014), 'Organizational identity and family business', in Melin, L., Nordqvist, M. and Sharma, P. (eds), The SAGE Handbook of Family Business 1st edn, Thousand Oaks, CA: SAGE, pp. 480-97. 